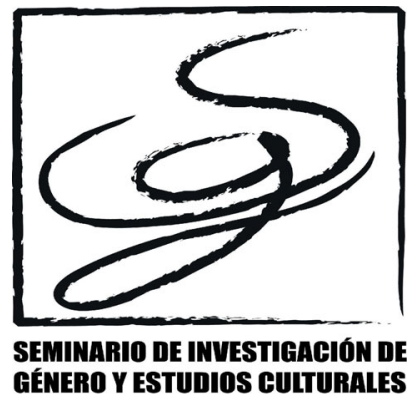

\title{
Narrativas estéticas como política de resistencia desde la experiencia femenina hondureña
}

\section{Aesthetic narratives as a politics of resistance from the Honduran female experience}

\author{
Silvia Gas Barrachina \\ Universitat Jaume I \\ sylviabarrachina@gmail.com
}

\author{
Fecha de recepción: 19/06/2020 Fecha de evaluación: 07/07/2020 \\ Fecha de aceptación: 30/11/2020
}

\begin{abstract}
:
Honduras is framed in a scenario of different kinds of violence that prevent the democratic progress of the country. The high rates of criminal violence are attributed to a problem among gangs that persists in a context of poverty and inequality. The resulting effect of this reductionist perspective approached by the State is the implantation of repressive measures towards society, instead of proposing preventive policies. Violences are hierarchized and assigned different values. In this sense, femicides are considered a minor problem. There is a lack of intention on the part of the institutions to solve these practices that favor impunity and affect the personal development of women. The aim of this paper is to examine the relationship between the particular Honduran context and the artistic representation of violence against women by women artists. These artists, from their condition, experience and reality, establish a political dialogue approached from the aesthetic language as an act of transformation and resistance. The strategies and narratives used by Honduran artists to highlight violence are examined For its analysis, the methodology used was based on feminist epistemological approaches that allow a reflective interpretation of the works proposed by the artists. The results obtained were the confirmation of the perpetuation of the patriarchal system that affects the artistic evolution developed by women. Likewise, the difficulty of making visible the hidden reality of violence which remains subject to a pact of silence instigated by the culture of fear that the institutions protect.
\end{abstract}

Keywords: women; art; Honduras; femicides; gender identity; violence representation 


\section{Resumen:}

Honduras se enmarca en un escenario de violencias de diferente índole que imposibilitan el progreso democrático del país. Las altas tasas de violencia criminal son adjudicadas a una problemática entre pandillas que persiste en un contexto de pobreza y desigualdad. El efecto resultante de esta perspectiva reduccionista, abordada por el Estado, implica la implantación de medidas represivas hacia la sociedad, en lugar de plantear políticas preventivas. Las violencias son jerarquizadas otorgándoles diferentes valores. En este sentido, los feminicidios son considerados como una problemática menor. Se observa una falta de intención por parte de las instituciones en solucionar estas prácticas que favorecen la impunidad y afectan al desarrollo personal de las mujeres. EI presente artículo tiene como objetivo examinar la relación entre el contexto particular hondureño y la representación artística de las violencias ejercidas hacia las mujeres. Las artistas, desde su condición, experiencia y realidad establecen un diálogo político abordado desde el lenguaje estético como acto transformador y de resistencia. ¿Cuáles son las estrategias y narrativas empleadas por las artistas hondureñas para evidenciar las violencias? Para su análisis, la metodología empleada se fundamentó en planteamientos epistemológicos feministas que permitieran una interpretación reflexiva de las obras propuestas por las artistas. Entre los resultados obtenidos de la indagación, se verificó la perpetuación del sistema patriarcal que afecta al devenir artístico desarrollado por las mujeres. Asimismo, la dificultad de hacer visible la realidad oculta, acerca de las violencias, que permanece sometida a un pacto de silencio instigado por la cultura del miedo que amparan las instituciones.

Palabras clave: mujeres; arte; Honduras; feminicidios; identidad de género; violencia; representación

\section{Introducción}

La realidad socio-política en Honduras se enmarca en una encrucijada de violencias ejercidas hacia la población, afectando al desarrollo emancipatorio de los sujetos. La violencia criminal constituye una problemática enraizada que ahonda en el devenir democrático de la sociedad hondureña. Atendiendo a las cifras oficiales, proporcionadas por el Observatorio de la Violencia de la Universidad Nacional Autónoma de Honduras (UNAH), la tasa nacional de homicidios en 2018 es de 41.4 por 100.000 habitantes. A pesar de que las cifras han disminuido respecto a los años 2011-2012, donde se alcanzaron los niveles más altos (86.5), la tasa de homicidios permanece elevada en relación a la media global ofrecida por la ONU de 6.1 en 2017. Respecto a los rangos de edad, el $70.4 \%$ de las muertes por homicidios se concentran entre los 15 y 39 años, incidiendo en la población joven y en edad productiva. Las tasas de muerte causadas por violencia criminal son menores en las mujeres, representando el $10.3 \%$ en relación al $89.7 \%$ que afecta a los hombres. 
Sin embargo, conforme informa el Observatorio de Igualdad de Género de América Latina y el Caribe, en 2018 Honduras presenta unas cifras elevadas en feminicidios alcanzando 5.1 por cada 100.000 habitantes,superado, únicamente, por El Salvador (6.8).

Los feminicidios, ${ }^{1}$ según informa el Boletín Muerte Violenta de Mujeres y Femicidios Enero Diciembre 2018 (ONV/UNAH-IUDPAS), se producen en su mayoría en la vía pública y con armas de fuego. Hay que destacar que el $62.4 \%$ de los casos corresponden a un rango entre 15 y 39 años de edad. Al categorizar los feminicidios, se establece que el $37.2 \%$ es producido por delincuencia organizada, $34.4 \%$ corresponde a feminicidios sin determinar (aquellos que no permiten categorización pero donde el contexto indica razones de género y se muestra ensañamiento contra el cuerpo femenino), $17.9 \%$ por feminicidio íntimo (cuando la víctima es la pareja, expareja o pretendiente), seguido de feminicidio por violencia sexual (cuando la víctima presenta agresiones sexuales) con el $6.4 \%$. La violencia criminal a pesar de ser la causa que muestra una mayor cifra de muertes violentas de mujeres no significa necesariamente que las víctimas "formen parte de actividades ilícitas, ya que muchas veces estos grupos organizados envían mensajes a través de los cuerpos de las mujeres» (Boletín Muerte Violenta de Mujeres y Femicidios,2018:9). Como se observa, las mujeres sufren violencias visibles simplemente por su condición femenina. Este hecho refleja la concepción predominante en el imaginario colectivo que relaciona a las mujeres con la debilidad, situadas en condiciones de desigualdad y sometidas a la supremacía de la figura del hombre que reproducen las estructuras institucionales patriarcales. Marcela Lagarde desarrolla el concepto de feminicidio, a partir del trabajo de Diana Russell y Jill Radford (1992), definiéndolo como:

El conjunto de formas de violencia que, en ocasiones, concluyen en asesinatos e incluso en suicidios de mujeres [...] preferí la voz feminicidio para denominar así al conjunto de delitos de lesa humanidad que contienen los crímenes, los secuestros y las desapariciones de niñas y mujeres en un cuadro de colapso institucional. Se trata de una fractura del Estado de derecho que favorece la impunidad. El feminicidio es un crimen de Estado (Lagarde, 2006: 20).

\footnotetext{
1 Desde el año 2013 el Código Penal de Honduras incluye el delito de Femicidio en el Artículo 118-A que implica una pena de treinta a cuarenta años de reclusión para los hombres que den muerte a una mujer por razones de género. Las circunstancias para ello residen en mantener una relación sentimental con la víctima, cuando el delito esté precedido de actos de violencia doméstica intrafamiliar, independientemente si hay denuncias, cuando el delito esté precedido de una situación de violencia sexual o acoso, y cuando se produce ensañamiento contra la víctima. El problema radica en la incapacidad de las instituciones de diagnosticar los femicidios y la consiguiente impunidad hacia quienes cometen este tipo de delito.
} 
En el contexto hondureño, el móvil que presenta este ámbito violento y criminal es determinado por una encrucijada entre el Estado y las maras o pandillas. Desde el Estado no se ejecutan políticas públicas para combatir las desigualdades de carácter estructural que interfieren en el desarrollo integral de la población. Los factores devenidos de la inequidad social, que afectan notablemente a la población joven y damnifican su desarrollo personal, se traducen en un difícil acceso a la educación, abandono de estudios para contribuir a la economía familiar, analfabetismo, desigualdad de oportunidades, difícil acceso a un empleo y dificultades para adquirir ingresos. En consecuencia, se dibuja un escenario marginal donde predomina la pobreza. Atendiendo a los datos proporcionados por el Banco Mundial, en 2018, el 48.3\% de la población hondureña vive en la pobreza, de los cuales el $60.1 \%$ corresponde a zonas rurales y el $38.4 \%$ a zonas urbanas. Esta violencia social practicada por el Estado muestra un marco óptimo para el desarrollo de actividades ilícitas, dando lugar al incremento de la violencia criminal. El crimen organizado, mediante maras o pandillas, penetra en la sociedad y la subyuga en base a los siguientes factores fundamentales: a) instigar a jóvenes a pertenecer a estos grupos con el fin de ampliar círculos y controlar territorios a pequeña escala, b) la predisposición de jóvenes a introducirse en estas pandillas como única vía de supervivencia y como modo de identificación acorde con su realidad, c) extorsionar a la población para adquirir fuentes de ingresos, d) controlar instituciones que permita el desarrollo de negocios ilícitos.

\begin{abstract}
La violencia criminal la ejercen grupos no para imponer una visión del mundo, ni para ejercer el poder político de forma directa, sino para controlar el territorio y poder operar sus negocios, transitar por los espacios, contar con la infraestructura que les permite funcionar. Su interés parece más visible en los poderes locales, en zonas de tránsito y fronterizas, en regiones aisladas pero estratégicas, y no hacia el poder nacional (Castellanos, 2017: 97).
\end{abstract}

La respuesta del Estado se fundamenta en el desarrollo de políticas a corto plazo caracterizadas por la represión institucional hacia el conjunto de la sociedad y militarización de las calles, en lugar de incidir y actuar sobre los orígenes de la problemática. La falta de voluntad política indica que «los niveles de violencia y criminalidad a los que llegó el país cuentan con la complicidad e involucramiento de una parte de las estructuras del Estado, incluyendo el sector empresarial, clave en el proceso de lavado de activos» (Castellanos, 2017:97). Se configura una espiral de violencia en la cual los elementos que forman parte se retroalimentan entre sí.

En el caso de las mujeres, por su condición femenina, están expuestas en mayor grado a un desamparo por parte de las instituciones. En el ámbito económico y laboral las mujeres tienen difícil acceso a la vida política y aquellas que lo logran sufren violencia. Atendiendo a la declaración de fin de misión del Grupo de Trabajo del Consejo de 
Derechos Humanos sobre la cuestión de la discriminación contra la mujer en la legislación y en la práctica de 2018, las expertas informan acerca de que «las mujeres que son candidatas a cargos públicos, a menudo se ven disuadidas de ser presentadas por las comunidades y los asociados, y se han convertido en blanco de la violencia política. Uno de nuestros interlocutores, por ejemplo, mencionó 14 casos de violencia contra las mujeres durante las elecciones y 44 casos de violencia contra las mujeres después de las elecciones» (Grupo de trabajo de la ONU, 2018). En el entorno laboral las tasas de desempleo son más altas en el caso de las mujeres. En 2018, conforme indican las estadisticas de CEPALSTAT ${ }^{2}$, las mujeres presentan una tasa de 7.4 y los hombres $4.5^{3}$. Asimismo, como advierten las relatoras, la violación de derechos laborales especialmente en el sector manufacturero de las maquilas y del servicio doméstico afecta gravemente a las mujeres. En el ámbito educativo, los casos de matriculación son ligeramente más altos en las mujeres. Sin embargo, el acceso a la educación está afectado por la falta de centros educativos sobre todo en zonas rurales. El sistema sanitario carece de servicios de salud sexual y reproductiva de calidad. Como informan las relatoras "las mujeres lesbianas, bisexuales, transgénero e intersexuales, las trabajadoras del sexo, mujeres en prostitución y las que viven con el VIH tienen menos acceso a una atención sanitaria de calidad debido a la estigmatización y a las actitudes discriminatorias sobre su identidad o su estado de salud» (Grupo de trabajo de la ONU, 2018). También, está prohibida la anticoncepción de emergencia y el aborto con penas para las madres de 3 a 6 años de prisión según el artículo 126 del Código Penal. Esta violencia ejercida hacia el cuerpo y salud de las mujeres es consecuencia de las desigualdades de género consumadas por el sistema patriarcal.

Un sistema que asesina a aquellas mujeres que han alzado su voz en defensa de sus derechos, han reclamado o han realizado cualquier acto no adscrito a su condición femenina. Véase el caso de las activistas por la defensa de los derechos medioambientales ${ }^{4}$ y comunidades indígenas como Berta Cáceres (asesinada en 2016), Blanca Jeannette Kawas Fernández (en 1995), Margarita Murillo (en 2014), Lesbia Urquía (en 2016), activistas por la defensa de los derechos de las personas LGBTIQ+ como Sherlyn Montoya (en 2017) y Paola Barraza (en 2016) o los casos de Riccy Mabel Martínez Sevilla (en 1991) y Clementina Suárez (en 1991). Estos asesinatos permanecen todavía en la impunidad. Como

\footnotetext{
${ }^{2}$ Recuperado de:

https://estadisticas.cepal.org/cepalstat/WEB_CEPALSTAT/estadisticasIndicadores.asp?i dioma $=\mathrm{e}$

${ }^{3}$ En 2015, la tasa de desempleo de las mujeres fue 11.7, cifra que ha disminuido progresivamente. No obstante, la tasa de desempleo masculino se ha mantenido estable.

${ }^{4}$ En el Informe de Global Witness, 2017, se determina a Honduras como el lugar más peligroso para defender el planeta debido a los continuos asesinatos de las y los activistas.
} 
indica el informe de la ONU (2018) $)^{5}$ aproximadamente el $97 \%$ de los crímenes cometidos contra defensores y defensoras de derechos humanos, siguen sin resolverse. Los efectos derivan en una desconfianza hacia las instituciones por la impunidad de los actos violentos y la incapacidad de garantizar el bienestar de la sociedad en general y de las mujeres en particular. La perpetuación de los roles de género se manifiesta en la legitimación de las violencias ejercidas, imposible de desarticular sin la voluntad de las instituciones, quienes a su vez sostienen dichas violencias.

\section{Revisión de la literatura}

Las imágenes generadas por las instituciones, los medios o el arte influyen en el proceso de la construcción identitaria de los sujetos. «Nos constituimos como sujetos marcados por condicionantes de género y de clase a través de ciertos procesos sociales. Nos vemos impelidos a reconocernos en las identidades e imágenes que nos transmiten determinadas prácticas e instituciones sociales» (En Alario,2008:9). Desde la aparición del arte feminista, en la década de los 70, las artistas van a exponer públicamente en sus obras su experiencia de ser mujer. Judy Chicago, Miriam Saphiro o Faith Wilding entre otras, cuestionaron los principios de la tradicional obra de arte así como la posición de las mujeres en el ámbito artístico y político-social. Una práctica que ha contribuido al desarrollo de la teoria feminista la cual, a su vez ha retroalimentado la creación artística. Linda Nochlin, Grisselda Pollock, Erika Borney, Maria Teresa Alario o Estrella de Diego son algunas de las mujeres que han investigado la relación entre arte y feminismo. En el contexto latinoamericano, Julia Antivilo en Entre lo sagrado y lo profano se tejen rebeldías: arte feminista nuestroamericano (2015) presenta prácticas artísticas que surgen en contextos específicos cercanos a las realidades de las mujeres y que subvierten las tradicionales prácticas institucionales. Andrea Giunta en Feminismo y arte latinoamericano: Historias de artistas que emanciparon el cuerpo (2018) expone la escena artística de los sesenta y ochenta, protagonizada por mujeres que presentan sus cuerpos como medio de emancipación y transformación. Asimismo, analiza la relación entre la acción artística feminista y el contexto político cuestionando la posible existencia de un arte feminista lationamericano. También es interesante destacar la labor de Mujeres en las Artes "Leticia de Oyuela" (MUA), asociación cultural que fomenta y promociona la práctica artística de mujeres hondureñas. No obstante, las publicaciones más allá de la visibilización de artistas no son abundantes respecto al ámbito particular hondureño.

${ }^{5}$ Declaración de fin de misión de Michel Forst, relator especial de las Naciones Unidas sobre la situación de los defensores y defensoras de los derechos humanos, 2018. https://www.ohchr.org/SP/NewsEvents/Pages/DisplayNews.aspx?NewsID=23063\&Langl $\mathrm{D}=\mathrm{S}$ 


\section{Objetivos}

La cuestión planteada en este trabajo reside en examinar la relación existente entre un marco de violencias ejercidas hacia las mujeres y las prácticas artísticas como herramienta de visibilización y vindicación de las experiencias de las mujeres hondureñas. En este sentido, "el arte es un modo de ver y un modo de ser, sin que necesite estar individualizado» (Duque,2001: 60). El arte constituye una herramienta para hacer visible, en este caso, los diálogos producidos entre las artistas y el contexto geopolítico en el que viven, fundamentado en sus experiencias. De este planteamiento surgue la siguiente pregunta de investigación: ¿Se manifiesta el contexto violento en la práctica artística de las mujeres hondureñas?

El objetivo del presente trabajo consiste en estudiar las narrativas artísticas desarrolladas por mujeres hondureñas situadas en el marco de violencias ejercidas en el contexto hondureño. Para ello, se determinan los siguientes objetivos específicos:

a) Analizar la presencia y visibilización de la obra de las mujeres en el contexto artístico.

b) Examinar cómo se representan y afrontan las violencias profesadas hacia las mujeres en el contexto institucional.

c) Identificar la posible existencia de un arte público que manifieste la realidad violenta de Honduras.

\section{Metodología}

Para tal fin, se hizo uso de una metodología feminista con el propósito de recuperar la presencia y aportaciones de las mujeres. El género fue empleado como categoría de análisis permitiendo explicar la forma diferenciada como las sociedades determinan los roles de acción. En primer lugar, se aplicó el método cuantitativo para definir los sujetos de estudio. Hay que señalar que para ello, la elección se justificó en: a) la relación con las instituciones, en concreto con Bienales por ser un evento donde se presentan propuestas innovadoras y se evalúa el carácter de la práctica artística, b) en oposición, las acciones artísticas planteadas en escenarios no institucionales más cercanos al público en general. Tras la consulta de los catálogos de las Bienales realizadas en Honduras: Bienal de Artes Plásticas UNAH (2014-2018), Bienal de Artes Visuales de Honduras BAVH (2006-2014), Bienal Centroamericana de las Artes Visuales (1998-2016) y la búsqueda de colectivos artísticos mediante el método de la bola de nieve, se procedió a la delimitación de los sujetos de estudio. La selección de la muestra final se efectuó en función de dos criterios específicos:a) nacionalidad hondureña de artistas o desarrollo de la práctica artística en Honduras, b) la violencia como eje central de la obra artística. Seguidamente, se realizó un análisis iconográfico e iconológico de las obras para diagnosticar aquellos elementos estéticos y narrativos referidos a la violencia. Mediante la interpretación de las obras, se relacionaron elementos y estrategias diversas en una teoría unificadora acorde con los objetivos planteados. 


\section{Resultados}

Los resultados obtenidos presentaron una visibilización menor del trabajo artístico realizado por mujeres. En la Bienal de Artes Visuales de Honduras BAVH celebrada de 2006 a 2014, sólo participaron 21 mujeres frente a 56 hombres. En la Bienal Artes Visuales UNAH de 2014 a 2018 participaron 13 mujeres y 58 hombres. En la Bienal Centroamericana de Artes Visuales de 1998 al 2016 participaron 117 mujeres y 253 hombres. Como se observa, la participación de las mujeres representó un total del $29,15 \%$ y la de los hombres un $70,85 \%$.

En cuanto al análisis de las obras seleccionadas en las Bienales, revelaron la ausencia de representación explícita de feminicidios o cualquier otro tipo de violencia ejercida hacia las mujeres. Únicamente el $3 \%$ de las obras realizadas por mujeres hizo referencia a la violencia. Entre ellas, destaca Perfil de ciudad (2006) de Xenia Mejía, conformada por dibujos sobre papel dispuestos en cuatro mesas que conforman figuras masculinas tendidas en el suelo. Los trazos del pincel y el predominio del color rojo envuelven la escena de carácter violento. La instalación Sucesos (2010) de Dominic Ayuso presenta la violencia desde una perspectiva de sanación, al envolver periódicos que hacen referencia a actos violentos en gasas quirúrjicas. El collage de Alma Leiva San Pedro Sula tiene cuerpo de mujer (2016) es la única obra que se refiere directamente a la violencia de género. En ella, presenta sobre papel rostros de víctimas junto con un mapa de la ciudad donde se situan códigos QR mostrando lugares en los cuales se produjeron actos violentos contra mujeres.

Al analizar el arte público situado al margen de las instituciones y de carácter reivindicativo se observó la manifestación de acciones de carácter artístico posicionadas en contra de la violencia. Colectivos como Culturas Vivas (mixto) y Dolls Clan (conformado sólo por mujeres) transforman el espacio público mediante el arte urbano desarrollando una labor de recuperación de la memoria colectiva y representación de la feminidad. En este contexto artístico tampoco se expresó ninguna referencia a los feminicidios.

\section{Discusión de los resultados}

\subsection{Visibilización de las artistas hondureñas}

Ante esta situación, cabría reflexionar acerca de la baja representación de la práctica artística realizada por mujeres. En primer lugar, hay que tener en cuenta que las bienales constituyen emplazamientos de visibilización, ya no únicamente de artistas sino también de un país o una ciudad. El problema que presenta este tipo de espacios reside en su politización debido a dos cuestiones fundamentales. Por un lado, la participación de los mismos y las mismas artistas frente a otros/as cuyas obras no se enclavan dentro de los parámetros artísticos establecidos por las Bienales. Además, la participación de las mujeres y sus trabajos son en menor medida visibles, hecho que muestra cómo las instituciones siguen preservando los roles 
de género que devienen en la figura masculina adscrita a la de genio creador. "La Bienal de Honduras tiene como objetivo convertirse en la plataforma que permita a artistas plásticos y visuales de Honduras, participar en otras Bienales a nivel internacional» (De Solzireé, 2016:20). Esto no quiere decir que no sean necesarias, ya que permiten conocer y hacer visibles las realidades de una zona a través de las experiencias vitales de artistas, sino más bien que necesitan de un cambio en su operatoria, puesto que:

\begin{abstract}
Las inauguraciones de las bienales se han vuelto un espacio de espectáculo para la socialización de los patrocinadores, la celebración de la institución, los críticos de oficio, medios de comunicación, artistas aburguesados y un séquito selectivo de fieles (De Solzireé, 2016:21).
\end{abstract}

Por otro, las instituciones limitan las prácticas artísticas fundamentadas en procesos intelectivos. «Reforzando modelos de tradición realista que únicamente valoran las destrezas técnicas y dominio de los géneros tradicionales» (Galeano, 2015:8). Desde el espacio que configura una Bienal se legitima aquello que se define como arte. Consecuentemente, «buena parte de nuestros artistas, (...) han sido victimas de la estrechez del mercado y de la inexistencia de gestores comerciales como galerías, ferias de arte, etc. Esta dinámica ha obligado a los creadores ha producir obras para satisfacer los gustos de una élite» (Galeano, 2015:10). En general, en las Bienales se evidencia una práctica artística sometida a los cánones políticos de las instituciones. Alejandra Mejía en una entrevista con motivo de su participación en la III Bienal del Sur: Pueblos en Resistencia afirmaba:

En Centroamérica hay una carencia de espacios para
el apoyo de artistas emergentes. Sí los hay, pero son
de difícil acceso en su mayoría. Otra motivación fue el
carácter político de la bienal, ese retorno a la
necesidad de hacer un tipo de arte que no solo llene
un espacio vacío, sino que también le importe entrar
en diálogo con la realidad en que vive, comunica y
objeta al espectador. Digo retorno porque pareciera
que se ha olvidado ese papel del arte como
transformador de la cultura, como parte del proceso
educativo que debería tener toda revolución, todo
movimiento progresista (Mejía,2020)

En segundo lugar, la falta de educación artística influye en que los y las artistas tengan que formarse autónomamente, trabajando de forma instintiva y guiándose por las pautas burócratas del arte. «La poca reflexión y la inexistencia de profesionales capaces que orienten los procesos creativos son problemas que no solo se manifiestan entre los creadores, sino también en el campo de la gestión, curaduría y crítica de

6 Recuperado de: https://albaciudad.org/2020/01/la-obra-precarios-de-la-artistahondurena-alejandra-mejia-romero-recorrera-varios-museos-del-pais-durante-2020/ 
arte» (Galeano, 2015:8). La educación artística en Honduras es limitada, ya que únicamente existen centros como la Escuela Nacional de Bellas Artes, fundada en 1940 y la licenciatura en Arte ofrecida por la Universidad Pedagógica Nacional Francisco Morazán desde 1977. La falta de compromiso de las instituciones se constata en la carencia de un presupuesto destinado a la educación artística. En consecuencia, se observa una práctica artística con escasa reflexión y producción de conocimiento estético.

\begin{abstract}
El comportamiento intuitivo que impera entre nuestros creadores -está claro que no es en todos los casosprobablemente sea por problemas de formación académica, técnica y científica y de un endeble capital cultural, pero también se debe a factores institucionales(Galeano, 2015:8).
\end{abstract}

Asimismo, la actividad artística se proyecta fragmentada, creando entidades culturales independientes ${ }^{7}$ que mejoran las condiciones para las exposiciones pero a la vez imposibilitan la construcción de un proyecto común. La sociedad no presenta intereses artísticos a causa de la falta de conocimientos y del poco valor otorgado a la práctica artística.

La falta de apoyo de las instituciones, el acceso limitado a la formación y reflexión artística y la carencia de un proyecto común que ponga en valor el arte hondureño, devienen en un marco que favorece la reproducción de los roles de género, puesto que la práctica artística sigue permaneciendo adscrita a la condición masculina. Hecho revelado en el escaso número de mujeres artistas hondureñas y su baja participación en las Bienales. Además, se observan dificultades en mostrar las realidades que envuelven a los/las artistas, al tener que adscribirse a la práctica legítima.

\title{
5.2. Representación de la violencia
}

Desde la propia experiencia de ser mujer en un contexto geopolítico marcado por circunstancias determinadas, se incide en una representación mediante una perspectiva intimista. Xenia Mejia (1958) en Memorias (1996) presenta una instalación en la cual aparecen posicionados en el suelo comales con caras de niños impresas y sobre el fondo se proyecta una reja donde se disponen biberones llenos de leche. La instalación nos remite a un emplazamiento encarcelado donde la infancia se abandona al devenir de un futuro desamparado. La cuestión acerca de las violencias ejercidas hacia los y las niñas es manifestada abiertamente en El vidrio de pandora (2018) de Dilcia Cortés (1990). En este trabajo se reivindican los derechos de los y las niñas mediante una serie de fotografías en blanco y negro. Los y las protagonistas son retratadas semidesnudas, en posiciones que exponen su fragilidad.

7 Centro de Arte y Cultura de la UNAH (CAC), Museo de Identidad Nacional (MIN), Centro Cultural de España (CCET), Galería Nacional de Arte y Mujeres en las Artes (MUA). 
Desprotegidos, sus cuerpos se envuelven en pinceladas rojas que acentúan la ira y dolor de quien observa y de quien es observado.

La violencia militar es expuesta en los trabajos de Alejandra Mejía (1985). Fauna (2010) representa una serie de fotografías minimalistas en blanco y negro donde aparecen elementos militares, tanques o misiles, sobre los que se añaden ilustraciones de personajes de Disney. La sensibilidad y la inocencia se imbrican con la violencia y crueldad configurando una unidad que emerge de dos mundos contrapuestos. Precarios (2017) y El Ruido animal (2012-2014) plantean un argumento de subordinación entre dos elementos definitorios de la cultura centroamericana. La naturaleza, la esencia del ser es atravesada por la materialidad de los objetos capitalistas, modelando un nuevo escenario frágil, pobre, deshumanizado. La violencia dibuja imágenes que la sociedad interpreta como naturales. En este juego poético la artista manifiesta la verdad de una realidad ocultada. La nube roja (2012), proyecto independiente sin figura curatorial, exhibe un fenómeno plasmado en una poética visual realmente conmovedora. Un trabajo impactante en el cual la sangre de hondureños y hondureñas es empleada como elemento central permitiendo enfrentar crudamente la violencia que sobrevuela centroamérica. Los grandes números representando los kilómetros cuadrados de superficie de cada país centroamericano, pintados con sangre, suscitan un crudo diálogo entre la obra y quien observa.

En la praxis artística de mujeres hondureñas se evidencia una ausencia de representación tanto de feminicidios como de cualquier práctica violenta ejercida directamente hacia las mujeres. Como se ha observado en los trabajos analizados, las violencias son expuestas desde la experiencia de las artistas, abordadas sutilmente en referencia a la infancia o bien, como es el caso de Alejandra Mejía como demostración de poder por parte de la hegemonía capitalista y sus consecuentes daños humanos y ecológicos. Son escasos los proyectos que recurren a la cuestión de la violencia criminal que ahonda en el país (en este análisis únicamente se ha localizado el trabajo La nube roja). Las causas de este vacío podrían devenir en diferentes argumentos. La realidad de los feminicidios permanece oculta, que no invisible, considerándose una cuestión comprometida. Hacerla visible, conlleva un enfrentamiento con las políticas artísticas institucionales por ser un tema de controversia, pero también con las políticas públicas. Las posibles consecuencias (quedarse fuera de los circuitos artísticos, no obtener financiación para el desarrollo de proyectos o espacios para exponer, enfrentar la cultura del miedo) limitan la acción de reivindicar y manifestar públicamente los derechos de las mujeres.

\subsection{Representación del cuerpo femenino}

Ante la ausencia de la representación de los feminicidios, cabe reflexionar acerca de cómo las propias mujeres escenifican sus experiencias. El cuerpo femenino en relación a la práctica artística, tal y 
como ocurre en el arte feminista, es configurado como emplazamiento de referencia a partir del cual establecer una (re)apropiación y reivindicación.

Celeste Ponce (1981), en Acid light (2008) presenta una narrativa donde vincula la erotización del cuerpo femenino con los objetos de consumo. Desde la publicidad se plantean estrategias donde el cuerpo de la mujer se articula como objeto sexualizado dispuesto a ser mirado. En este trabajo, los planos detalle de labios sosteniendo productos comerciales, proponen una denuncia partiendo de la visibilización erótica del cuerpo femenino como elemento de consumo. La sexualidad y el sexo se emplean para entablar un diálogo que rompa las estructuras dominantes acerca del género. Cariñositos (2008) y Mellizas (2008) de Dina Lagos (1983), simbolizan penes erectos realizados en felpa. El empleo de este material enlaza un signo de masculinidad con su condición pueril. El humor y la ironía constituyen el principio estratégico desde el que abordar el placer de lo erótico. Lía Vallejo (1992) en Economía del Placer (2016) representa la sexualidad de un modo explícito abordada desde la moralidad. En las ilustraciones los cuerpos se abandonan en una atmósfera surrealista de gozo y diversión, reivindicando la búsqueda y libertad del placer más allá del coito convencional centrado en los genitales. Scars of cold kisses (2016) de Andrea Fonseca (1989) plantea la erótica del placer en sus ilustraciones de pequeño formato. Los planos detalle de cuerpos en un acto sexual reclaman la visibilización y libertad del placer.

Desde otra perspectiva, el cuerpo femenino es tratado como lugar de memoria. Ser y tiempo (2014) constituye un trabajo de autorreflexión y autoexploración de la condición femenina. Claudia Bardales (1981) expone autorretratos fragmentados de su propio cuerpo. En una línea similar Dilcia Cortés (1990) y Celsa Flores (1952) proponen un proyecto conjunto titulado La Urdimbre (2016), donde el cuerpo femenino entelado es el protagonista de una serie fotográfica en blanco y negro. Esta obra surgió de la imbricación del trabajo de Dilcia Cortés con tejidos y el proyecto fotográfico de Celsa Flores como denuncia de la violencia de género.

Johanna Montero Matamoros (1980) en Hermanas (2017) presenta una xilografía donde aparecen dos mujeres de espaldas con la cabeza alta observando el horizonte, dibujado en un campo de cultivo. Imagen que nos evoca a la sororidad y lucha común para alcanzar un futuro mejor. Juliana Fuenzalida (1985) visibiliza en Luché y me callaron (2015) a aquellas mujeres que han permanecido invisibles y obviadas. El trabajo de Leticia Banegas (1978) presenta un recorrido hacia la tradición y las experiencias personales. El conjunto de sus obras como Orgullosa (2015) - Yo soy Madre (2016) muestran un mundo fantástico lleno de color habitado por mujeres fuertes y luchadoras.

Las narrativas constituidas en torno al cuerpo femenino devienen en una autorreflexión sobre el significado de ser mujer en el contexto hondureño. La vindicación de mujeres fuertes y luchadoras, la denuncia de la erotización de los cuerpos femeninos y la reivindicación de la libertad del placer sexual comprenden vías de reflexión constituidas a 
partir de la propia experiencia. En cuanto a las estrategias artísticas para plasmar estas narrativas, se observa una representación fragmentada del cuerpo femenino. En pocas ocasiones aparece un cuerpo desnudo en su totalidad, ya que la desnudez es considerada una cuestión controvertida. Cuando se representa se hace a través de ilustraciones y no se refiere directamente a la mujer sino a la libertad del placer sexual. En este sentido, se observa cómo las generaciones más jóvenes de artistas son más transgresoras al emplear el cuerpo desnudo como elemento central de su obra.

\subsection{Arte público, arte político}

Frente al arte situado dentro de los márgenes institucionales, hay que destacar las campañas reivindicativas que se apropian de lenguajes artísticos con el fin de establecer un ejercicio de visibilización y resistencia política frente a las realidades sociales.

En 2011 un grupo de jóvenes en los entornos de la Universidad Nacional Autónoma, iniciaron la campaña anti-chepística ${ }^{8}$ con objeto de denunciar la presencia de militares y policías en los espacios públicos, así como el control ejercido en el ámbito privado. Deslegitimar la militarización y la violencia fueron las ideas centrales de la campaña. En una entrevista para AmecoPres ${ }^{9}$ una de las participantes en la campaña, Gabriela Rueda, afirmaba:

La idea surge de la realidad hondureña, de la realidad de las mujeres, de estar viviendo en un estado de militarización, en un estado policiaco y de la necesidad de denunciar el creciente índice de asesinatos de jóvenes, hombres y mujeres. Además, de la necesidad de denunciar las causas estructurales de la violencia que vivimos en el país, más allá de la policía y las fuerzas armadas, señalando con claridad a estos sujetos que son quienes poseen las armas y están entrenados para usarlas (Rueda, 2011) ${ }^{10}$.

Mediante espacios virtuales (como el blog antichepística) iban narrando las diferentes acciones practicadas, las cuales se plantearon en dos fases. Una primera etapa consistió en militarizar la Universidad. Para ello, se representaron cuerpos asesinados, mediante siluetas manchadas con pintura roja simulando haber sido víctimas de disparos que yacían en el suelo y a través de bolsas de basura, simulando cadáveres encostalados, situadas dentro de toneles. También se dispusieron en el suelo zapatos con etiquetas de nombres de personas asesinadas. La segunda fase de desmilitarización consistió en transformar los elementos empleados en la acción anterior. Se pintaron con colores llamativos los toneles donde se disponian los cadáveres y se transformaron los zapatos

${ }^{8}$ El término chepo es empleado en el argot popular de Honduras para referirse a la policía.

9 Agencia de comunicación que forma parte de AMECO (Asociación Española de Mujeres Profesionales de los Medios de Comunicación).

10 Recuperado de: https://amecopress.net/Honduras-Arte-feminismo-y-subversion-8500 
en macetas con flores, simulando el florecer de la vida. Diversos diarios informaron sobre las acciones con los siguientes titulares: «Universitarios hacen 'singular' protesta contra la violencia» en el diario Proceso digital. ${ }^{11}$ En el diario El Heraldo: «Universitarios repudian corrupción policial» ${ }^{12}$ y en La Prensa: «Estudiantes de la Unah protestan contra la corrupción policial ${ }^{13}$. Desde el colectivo defendían su posición en contra de la militarización y no de la corrupción policial como se afirmaba en los titulares.

En 2019 el Colectivo Culturas Vivas intervino diversos espacios del mercado de Mama Chepa en Comayagüela. El fin consistió en pintar murales retratando a mujeres trabajadoras del mercado. Estas mujeres sufren unas condiciones de vida difíciles, permaneciendo obviadas por el Estado. En el mercado de Cantarranas se intervino el espacio público pintando murales en una iniciativa reivindicativa donde se homenajea a personalidades ilustres latinoamericanas como Berta Cáceres. El diario El Heraldo informaba con el títular: "Artistas urbanos reviven la capital de Honduras ${ }^{14}$ centrándose en el carácter artístico. Sin embargo, el medio digital hondureño ContraCorriente titulaba la noticia: «Mama Chepa: Delantales, murales y lucha» ${ }^{15}$. En referencia al carácter reivindicativo de las obras sobre la situación de las mujeres.

El grafiti constituye una herramienta poderosa en la reivindicación y apropiamiento de los espacios públicos. Dolls Clan, el primer grupo de grafiteras feministas, desafían los convencionalismos de género mediante sus murales. En sus trabajos enfrentan el espacio público con el fin de visibilizar la opresión a la que viven sometidas las mujeres, dialogando abiertamente y directamente con la sociedad acerca de cuestiones consideradas tabú como los feminicidios y los derechos reproductivos. Sus murales se componen de mensajes y retratos reivindicativos de los problemas que afectan a las mujeres como El mural de las hermanas Mirabal, activistas dominicanas asesinadas o La decisión es mía que alude a la libertad de las mujeres a tomar decisiones sobre su propio cuerpo.

A diferencia del arte institucional se observa como el arte público se refiere directamente a la violencia criminal y los derechos de las mujeres. De esta manera, se constituye una relación entre los espacios y la práctica artística.La historia contada desde las experiencias femeninas se construye a través de una vía más directa y reivindicativa en relación al espacio público. En el contexto hondureño, el espacio público es significativo en relación a dos aspectos esenciales. En primer lugar, las

11 Recuperado de: https://proceso.hn/universitarios-hacen-singular-protesta-contra-laviolencia/

12 Recuperado de: http://justnewshn.blogspot.com/2011/11/universitarios-repudiancorrupcion.html

13 Recuperado de: https://www.laprensa.hn/honduras/tegucigalpa/333934411/estudiantes-de-la-unah-protestan-contra-la-corrupci\%C3\%B3n-policial?i=29

14 Recuperado de: https://www.elheraldo.hn/pais/1331603-466/artistas-urbanos-revivenla-capital-de-honduras

15 Recuperado de: https://contracorriente.red/2020/01/22/mama-chepa-delantalesmurales-y-lucha/ 
pandillas se apropian de los espacios mediante pintadas en murales donde dejan mensajes y marcan su territorio.Utilizar los murales como elementos básicos de la práctica artística constituye un acto reivindicativo a favor de la cultura y desligitimación de la violencia. En segundo lugar, no todos los individuos que componen la sociedad hondureña tienen acceso a espacios culturales. Trasladar el arte de las instituciones a las calles implica un diálogo cultural permanente entre el arte y la sociedad.

\section{Conclusiones}

El contexto sociopolítico en el que se enmarca Honduras en cuanto a las violencias ejercidas hacia la población en general y hacia las mujeres en particular invita a reflexionar sobre su relación con la práctica artística. La falta de apoyo por parte del Estado hacia la educación y las instituciones artísticas configura un marco definido por la ausencia de reflexión y creación estética. Consecuentemente, la sociedad hondureña en general no mantiene un interés permanente en cuestiones artísticas. Asimismo, el arte legitimado por las instituciones determina los cánones estéticos que se deben seguir para ser aceptado en los circuitos artísticos. Aquellas narrativas que no permanezcan dentro de los parámetros establecidos quedan excluidas. De esta manera, la visibilización de las experiencias femeninas permanecen reducidas, limitadas y sometidas a los planteamientos canónicos.

Las técnicas empleadas por las artistas en la reproducción de sus obras son en su mayoria ilustración y fotografía, hecho que confirma el aprendizaje autónomo y la dificultad de acceso a una educación artística. En cuanto a las narrativas empleadas en relación a las violencias que padecen las mujeres, no se ha localizado obra que represente los feminicidios. Esto puede ser debido a la dificultad de visibilizar una realidad considerada controvertida. Los posibles efectos de evidenciar públicamente las violencias ejercidas hacia las mujeres infieren en un enfrentamiento con las políticas institucionales artísticas y con la cultura del miedo. Estos hechos limitan las acciones de denuncia y visibilización desde la práctica artística.

Sin embargo, sí que se cuestiona la violencia padecida en la infancia, la erotización del cuerpo femenino como objeto de consumo y los estereotipos de género. También se observa una crítica hacia las altas tasas de violencia criminal, aunque en menor medida, puesto que esta cuestión resulta controvertida. Respecto a la representación del cuerpo femenino, predominan los retratos o imágenes del cuerpo fragmentado. En pocas ocasiones aparece el cuerpo femenino desnudo porque es considerado un aspecto polémico. Hay que resaltar que aquellos trabajos que aluden directamente a la representación sexual de los cuerpos no se refieren únicamente al cuerpo femenino sino que van acompañados de cuerpos masculinos. Las representaciones del cuerpo femenino son referidas desde una perspectiva intimista que simboliza la sororidad y fuerza de las mujeres frente a un contexto que las oprime.

El arte es afectado por el ámbito violento en el que se enmarca Honduras en tanto que condiciona la práctica artística. En este sentido, 
los espacios públicos se configuran como una alternativa para establecer un diálogo reivindicativo con la sociedad que permite desde la propia experiencia comprender y develar realidades ocultadas. Este es el caso de Dolls Clan, un colectivo configurado por dos artistas grafiteras, autodenominadas feministas, cuyo trabajo es distinguido en un mundo considerado de hombres. Se contempla cómo las generaciones más jóvenes se apropian del discurso feminista para emplearlo en la práctica artística.

En este artículo se ha ilustrado una panorámica general de la producción artística de mujeres enmarcada en un contexto violento. No obstante, en trabajos futuros se vislumbra la necesidad de indagar en dicha relación así como la presencia y limitaciones de las mujeres (creadoras, comisarias, etc.) en diferentes espacios arísticos.

\section{Referencias bibliográficas}

AlARIO, Mํ Teresa. Arte y feminismo. San Sebartián: Nerea, 2008.

Base de datos de Estadísticas de homicidios internacionales de la Oficina de las Naciones Unidas contra la Droga y el Delito. Recuperado de: https://datos. bancomundial.org/indicator/VC.IHR.PSRC.P5?end=2017\&st art=1990\&view=chart

Boletín Muerte Violenta de Mujeres y Femicidios Enero-Diciembre 2018 (ONV/UNAHIUDPAS).Recuperado

:https://iudpas.unah.edu.hn/observatorio-de-la-violencia/boletines-delobservatorio-2/unidad-de-género

Boletín Nacional Enero- Diciembre 2018 - Ed №52 Observatorio de la Violencia de la Universidad Nacional Autónoma de Honduras (UNAH) Recuperado de: https://iudpas.unah.edu.hn/observatorio-de-la-violencia/boletines-delobservatorio-2/boletines-nacionales

CASTELLANOS, Julieta. "Honduras: violencia y procesos políticos". En Democracia, elecciones y violencia en América Latina.Romeo, Salvador (ed.),79-99. Honduras: Instituto Universitario en Democracia, Paz y Seguridad (IUDPAS), 2017.

CHINCHILLA, Laura. "Cartografías Paranoicas.Espacio y violencia en la producción cultural hondureña reciente". Centroamericana 27.2 (2017): 728.

Código Penal Honduras. Recuperado de: http://www.poderjudicial.gob.hn/CEDIJ/Leyes/Documents/CodigoPenalReformalncluida.pdf

DE SOLZIREÉ, Luz. De la posmodernidad y las artes visuales en Honduras a través de las bienales. Arte y cultura. 2.1 (2016): 14-23.

DOBINGER, Josefina. Recordar para volver al corazón. El cuerpo territorio de sentido y resistencia. Tegucigalpa: MUA, 2017.

DUQUE, Félix. Arte público y espacio político. Akal, 2001.

GaleANO, Gabriel "Rumbo 5 y sus relaciones contextuales". Arte y cultura. 2.1 (2015): 4-13. 
El Banco Mundial en Honduras. Tasas de pobreza. Recuperado de: https://www.bancomundial.org/es/country/honduras/overview

GLOBAL WITNESS."Honduras: El país más peligroso del mundo para el activismo ambiental", 2017.

GoLD, Janet. Culture and Customs of Honduras. London: GreenWood Press, 2009.

GRUPO DE TRABAJO DE L A ONU SOBRE LA CUESTIÓN DE LA DISCRIMINACIÓN CONTRA LA MUJER EN LA LEGISLACIÓN Y EN LA PRÁCTICA. Recuperado de: https://www.ohchr.org/SP/NewsEvents/Pages/DisplayNews.aspx?NewsID $=23873 \&$ LangID $=S$

LAGARDE, Marcela. Los cautiverios de las mujeres: madresposas, monjas, putas, presas y locas. México: Universidad Autónoma de México, 2006.

LANZA,Carlos \& CABALleRo,Ramón (eds.). Contrapunto de la forma. Ensayos críticos sobre arte hondureño y centroamericano. Honduras: Cultura, 2017.

LARACH, Gustavo. "Tendencias del arte contemporáneo en honduras: tres estudios de caso".

DOBINGER, Josefina. "Realidad visible e invisible: fosas colectivas del olvido recordadas en la memoria del cuerpo". Innovare, 2 (2018): 68-87.

Observatorio de Igualdad de Género de América Latina y el Caribe Recuperado de: https://oig.cepal.org/es/indicadores/feminicidio

ORTEGA, Visitación. "EL artivismo como acción estratégica de nuevas narrativas artístico-políticas". Calle 14: revista de investigación en el campo del arte, 10(2015):100-111.

OYUELA, Leticia. Mujer Familia y Sociedad. Honduras: Guaymuras, 2001.

RUEDA, Gabriela (2011). En Morales. Tacuziana (20 de diciembre de 2011). Honduras: Arte, feminismo y subversión. AmecoPress. Recuperado de: https://www.amecopress.net/Honduras-Arte-feminismo-y-subversion8500.

QUILES, Fernando \& Quiñone, Ana Cielo et al (eds.). "Como Bálsamo de Fierabrás. Cultura en tiempos y territorios en conflicto". Cuadernos del Aula, 4 (2018).

QUIÑONES, Emilia. “La violencia de género en el arte de la generación Mesótica II". C I E H L, 23 (2016): 157-168. 